\title{
Review of Mark Carrigan and Lambros Fatsis (2021). The Public and Their Platforms: Public Sociology in an Era of Social Media
}

\author{
Bristol: Bristol University Press. 242 pp. ISBN 9781529201055 \\ (Hardcover)
}

\section{Naomi Barnes ${ }^{1}$ D}

Accepted: 17 August 2021 / Published online: 31 August 2021

(c) The Author(s), under exclusive licence to Springer Nature Switzerland AG 2021

\section{Sociology in a Post-pandemic and Postdigital World}

How does sociology adapt to the post-pandemic and postdigital world? In their book-cum-manifesto for public sociology, Mark Carrigan and Lambros Fatsis explore what it means to be public-facing sociologists. I say manifesto because though Carrigan has been arguing for how academics can use social media for close to a decade, having previously published two editions of a guide for academics wanting to move online (see Carrigan 2019 for the most recent edition). This book has a different energy about it, probably due to the addition of Fatsis to the authorship, but also likely due to the writing of it during the Covid-19 pandemic and mass migration of education online.

Maybe it is because I am writing this review for a journal titled Postdigital Science and Education and the authors and myself are connected to the blog site the 'Post-Pandemic University', ${ }^{1}$ but the repetitive insistence that we have moved beyond both the digital revolution at the same time as looking to the future of online education produces a sense of inevitability. There are two pandemics at play, both spreading across the world via human and electrified networks, and we cannot do anything about either of them except learn to live ethically alongside them. We are in the 'posts' so what do we do now?

Carrigan and Fatsis' book includes eight essays which systematically, with all the traditional markers of sociology, takes the reader through their argument. Building

\footnotetext{
1 See https://postpandemicuniversity.net/. Accessed 16 August 2021.
}

Naomi Barnes

n3.barnes@qut.edu.au

1 Queensland University of Technology, Brisbane, Australia 
from definitions of 'the Public', tracing a history of Platforms, exploring the interplay between the two, and finishing with a model for what online public sociology could be. But if you start with the final chapter, the point of the book, it is a manifesto for how sociologists can use online spaces and rescue the discipline, despite cuts to university Humanities and Social Science courses. If sociology is to survive the dual pandemics, the thousands of academics with the skills to tell the human stories of statistical data must face the inevitable and cliched 'pivot' to online. Carrigan and Fatsis' essays unpack why that is necessary and how it can be done, leaving no definition uninterrogated.

\section{So, Let's Unpack That Manifesto}

In Chapter 8, 'Assembling Public Sociology', Carrigan and Fatsis (2021: 183) start with the claim that previous public approaches to sociology have had a 'scholastic predisposition towards thinking rather than doing' (emphasis in original). Not willing to dismiss the history of thinking in sociology, and quite apologetic for being so brazen as to suggest it, the authors spent the first seven chapters tracing the theory which led them to their call for action. The point of the book being a plea to sociologists to reinvent their discipline in the postdigital post-pandemic world, or risk it going the way of other humanities and social sciences that have died when faced with modernising processes, like Latin.

The core of the appeal for a new way of seeing what a sociologist is. Sociology is currently valued in an economic sense: it is a profession which is aligned to an institution and that institution pays for sociology. Carrigan and Fatsis' desire for sociology to come out from the oppression of privatisation, depoliticisation, and standardisation is an inspiring one. Their proposal is that sociology should stop looking at itself as a commodity and think about itself as a public good.

The model they propose is two tiered: that sociologists create online spaces where they can converse with each other (thinking) and communicate with the public (practical action). They propose a network of scholarship via blogs and online forums to discuss issues in scholarship and develop the thinking, but also how to become outward facing with the communities these ideas effect. One of the mantras in educational sociology that springs to mind is that education research needs to be with schools rather than about schools. Carrigan and Fatsis' imagination for public sociology seems to channel that sentiment.

I must admit that I responded to this rhetoric, using my skills for telling the human stories behind the statistical data that dominated discourse around Covid19 outbreaks in schools. I saw it as an opportunity to talk about how school communities work, attempting to cut through a media cycle dominated by the statistical wars of the health and economic systems.

Interrogating my own commodification of sociology through this experiment with public sociology, I must ask Carrigan and Fatsis: How does one get paid to do this job without a university? The story I told was also tangential to what I research (networks within education policy), so my next question is: How does one speak 
authoritatively about sociology when most of the individual sociologists' research is so niche? I explore both of these questions below.

\section{The Authority of Sociology}

Carrigan and Fatsis discuss how professional sociology draws its authority from the institution it is associated with. When an academic appears in the media to add comment to the continuous news analysis, they are selected because they have 'Dr.' in their title and are considered even more distinguished when a prestigious university is attached to their name. Carrigan and Fatsis argue that public sociology that works as a form of civic action must be separated from professional sociology that provides comment.

The authors argue that public sociology should be completely different, providing online places and spaces to study sociology, what they call 'de-schooling' the discipline to be something that is achieved together, through a learning network (reminiscent of Illich 1971) rather than explicitly taught and controlled from a central institution. The argument is reminiscent of similar debates in the schooling system between direct instruction and inquiry. Is the role of a teacher, who is a professional knowledgeable person, to tell students the answer for students to learn? Or is the role of a teacher to guide students in exploring a phenomenon or topic, ensuring that important knowledge is encountered along the way?

It is interesting that Carrigan and Fatsis are positing a similar dichotomy for public sociology. The difference being that Carrigan and Fatsis are not arguing for one over the other, rather that what we currently see as public sociology is not necessarily deeply educative because it simply tells people the stories. Their manifesto sets out a vision for an alternative.

They refer to this alternative as the 'digital undercommons' (Carrigan and Fatsis 2021: 183) where platforms are used to enable a public sociologist's civic mindedness, not simply a place to publish and spruke their publications. I have previously explored this possibility through writing with teachers and academics about digital labour (Barnes and Netolicky 2019; Lennon and Barnes 2020). These relationships were positive and both parties actively engaged in trying to understand the world from each other's point of view. Being involved in studies of digital labour and education has meant that I can see the exploitative nature of online spaces dedicated to civic mindedness and must issue the authors a caution.

The online magazine 'Post-Pandemic University' is obviously an attempt to put this vision into practice. On this site, sociologists and the sociologically minded are encouraged to post explanatory and subversive articles about the state of the university in the postdigital world. In that space, there have been articles criticising university conditions that characterise higher education as a business rather than a place of scholarship. This type of writing, for the precarious, is both liberating and dangerous. I believe that while this approach is laudable, it is important that such a project is gentle with people who want to become professional sociologists. 
Scholarship into academics discussing their work online is very clear about how women and people from minority and non-Western backgrounds have been silenced by the development of platform scholarship (Pitcan et al. 2018). As expectations of universities include online interaction, many people are choosing to avoid researching topics which are considered dangerous. While a sociological platform that allows people to expose concerns, they have about universities is a civic good, are the people writing for 'Post-Pandemic University' completely cognisant of the vision?

'Post-Pandemic University' must make it very clear, in a world of publish or perish, that critiquing the institution one might want to enter, to develop a track record, will work differently for different people. What might gain an established and wellknown academic a career as a professional academic in a university might very well destroy such an ambition for a little-known early career or higher degree researcher.

\section{Privatization of Sociology in Educational Institutions}

There is a lot of scholarship, including Carrigan's, written about the purpose of social media in promoting academic work, which connects an academic's success in the impact and engagement agenda to the metrics associated with their scholarship. This journal has a whole special issue dedicated to it. ${ }^{2}$ This commodification of scholarship has seen some articles focus on the reaction they can get from Twitter, and the important issues that are being highlighted drowned out by the noise of that reaction (see Barnes 2020 for an example of this).

Carrigan and Fatsis hope that a shift in how public sociology is perceived will allow sociologists to take back control of this process of altmetric stardom, but also the need to be silent on certain issues. My question for the authors is, how does public sociology then get funded? People have committed their lives to the pursuit of sociology as a career and hope to support their families via that career. This is the piece of logic that I can't yet grasp about Carrigan and Fatsis's vision. Do sociologists still need to be employed by universities in order to be public sociologists? Are public sociologists, professional sociologists but with a different approach to scholarship? Is The Public and its Platforms an exercise in cruel optimism (Berlant 2011)?

Despite this disquiet about the manifesto that is The Public and Their Platforms (Carrigan and Fatsis 2021), I do believe that these ideas need to be made public so that they can be publicly engaged with. There is no sense in staying silent about a pressing need for sociology to take a good hard look at itself, without proposing how. I propose that Carrigan and Fatsis have outlined a perfectly suitable provocation and platform for debate about sociology and the public in the postdigital world.

\footnotetext{
${ }^{2}$ See https://link.springer.com/journal/42438/volumes-and-issues/3-1. Accessed 16 August 2021.
} 


\section{References}

Barnes, N. (2020). Navigating algorithms and affective communities in the quest for altmetric stardom. Impact of Social Sciences, 9 September. https://blogs.lse.ac.uk/impactofsocialsciences/2020/09/09/navigatingalgorithms-and-affective-communities-in-the-quest-for-altmetric-stardom/. Accessed 16 August 2021.

Barnes, N., \& Netolicky, D. M. (2019). Cutting apart together: A diffracted spatial history of an online scholarly relationship. International Journal of Qualitative Studies in Education, 32(4), 380-393. https://doi.org/10.1080/09518398.2018.1548038.

Berlant, L. (2011). Cruel Optimism (Illustrated edition). Durham, NC: Duke University Press.

Carrigan, M. (2019). Social Media for Academics (2 edition). SAGE Publications Ltd.

Carrigan, M., \& Fatsis, L. (2021). The Public and Their Platforms: Public Sociology in an Era of Social Media. Bristol: Bristol University Press.

Illich, I. (1971). Deschooling society. New York: HarperCollins.

Lennon, S., \& Barnes, N. (2020). A New Materialist take on the possibilities and impossibilities of becoming a scholarly blogger. International Journal for Academic Development, 25(3), 247-158. https://doi.org/10.1080/1360144X.2019.1704411.

Pitcan, M., Marwick, A. E., \& Boyd, D. (2018). Performing a Vanilla Self: Respectability Politics, Social Class, and the Digital World. Journal of Computer-Mediated Communication, 23(3), 163-179. https://doi.org/10.1093/jcmc/zmy008. 